\title{
ZONEAMENTO ECOLÓGICO DE PEQUENA ESCALA PARA ESPÉCIES FLORESTAIS TRADICIONAIS NO DISTRITO FEDERAL
}

\author{
Raquel Fernandes de Araújo ${ }^{1}$, Eraldo Aparecido Trondoli Matricardi ${ }^{2}$, Mauro Eloi Nappo ${ }^{3}$ \\ ${ }^{1}$ Eng ${ }^{\mathrm{a}}$ Florestal, Depto. de Engenharia Florestal, UnB, Brasília, DF, Brasil - veloziacea@ gmail.com \\ ${ }^{2}$ Eng. Florestal, Dr., Depto. de Engenharia Florestal, UnB, Brasília, DF, Brasil - ematricardi@ gmail.com \\ ${ }^{3}$ Eng. Florestal, Dr., Depto. de Engenharia Florestal, UnB, Brasília, DF, Brasil - mauronappo@ yahoo.com.br
}

Recebido para publicação: 27/10/2010 - Aceito para publicação: 29/02/2012

\begin{abstract}
Resumo
Neste estudo foram analisadas variáveis biofísicas para definir áreas potenciais para o plantio de espécies florestais tradicionais no território do Distrito Federal. As espécies testadas foram Pinus caribaea Morelet var. caribaea, P. caribaea Morelet var. hondurensis (Sénécl.) W. H. G. Barrett \& Golfari, P. caribaea Morelet var. bahamensis (Griseb.) W. H. G. Barrett \& Golfari, P. elliottii Engelm. var. elliottii, Eucalyptus camaldulensis Dehnh., E. urophylla S. T. Blake, E. grandis W. Hill, Corymbia citriodora (Hook.) K. D. Hill \& L. A. S. Johnson (ex Eucalyptus citriodora), C. torelliana (F. Muell.) K. D. Hill \& L. A. S. Johnson (ex Eucalyptus torelliana), Hevea brasiliensis (Willd. ex A. Juss.) Müll. Arg. e Tectona grandis L. f. Para identificar as áreas aptas para a implantação dos povoamentos florestais, foi realizada a sobreposição de variáveis do meio físico do Distrito Federal com variáveis relacionadas às exigências adaptativas de cada espécie estudada. Com base nos resultados desta pesquisa, as espécies que apresentaram potencial para cultivo nas condições físicas do Distrito Federal foram as três variedades de Pinus caribaea, P. elliottii var. elliottii, Eucalyptus camaldulensis, E. urophylla, E. grandis e Corymbia citriodora. As espécies Corymbia torelliana, Hevea brasiliensis e Tectona grandis não apresentaram potencial para o cultivo.

Palavras-chave: Silvicultura; sistema de informação geográfica.
\end{abstract}

\begin{abstract}
Small scale ecological zoning of Distrito Federal, Brazil, for traditional forest species. This study evaluated biophysical variables to identify suitable areas of the Distrito Federal for planting traditional tree species. The studied tree species included Pinus caribaea Morelet var. caribaea, $P$. caribaea Morelet var. hondurensis (Sénécl.) W. H. G. Barrett \& Golfari, P. caribaea Morelet var. bahamensis (Griseb.) W. H. G. Barrett \& Golfari, P. elliottii Engelm. var. elliottii, Eucalyptus camaldulensis Dehnh., E. urophylla S. T. Blake, E. grandis W. Hill, Corymbia citriodora (Hook.) K. D. Hill \& L. A. S. Johnson (ex Eucalyptus citriodora), C. torelliana (F. Muell.) K. D. Hill \& L. A. S. Johnson (ex Eucalyptus torelliana), Hevea brasiliensis (Willd. ex A. Juss.) Müll. Arg. and Tectona grandis L. f. Suitable areas for the studied tree species were identified by overlapping biophysical variables of the Distrito Federal, wich included adaptive tree requirements and site characteristics. Based on this research results, the territory of the study area is suitable for cultivation of three varieties of Pinus caribaea, P. elliottii var. elliottii, Eucalyptus camaldulensis, E. urophylla, E. grandis and Corymbia citriodora. There were no suitable areas for cultivation of Corymbia torelliana, Hevea brasiliensis and Tectona grandis.

Keywords: Silviculture; geographic information system.
\end{abstract}

\section{INTRODUÇÃO}

Os cultivos florestais desempenham o suprimento da demanda de madeira para os mais diversos fins. De acordo com Silva et al. (2004), a maior parte dos plantios florestais no Brasil tem como objetivo a produção de lenha, carvão, postes, escoramento, serraria e fabricação de papel. Para Carvalho et al. (2005), a indústria de celulose e papel é a mais bem sucedida do setor florestal brasileiro. A cadeia produtiva do setor abrange as etapas de produção de madeira, energia, celulose e papel, conversão em 
artefatos de papel e papelão, reciclagem de papel, produção gráfica e editorial, além de atividades de comércio, distribuição e transporte.

A demanda de madeira no Brasil é suprida em grande parte por povoamentos florestais de produção. Estes incluem principalmente as espécies de pinus e eucalipto e cerca de 370 mil hectares plantados com outros gêneros, como acácia (Acacia spp.), seringueira (Hevea brasiliensis), teca (Tectona grandis) e araucária (Araucaria angustifolia), entre outros (DUBOC, 2008).

O Brasil é o quarto maior produtor mundial de madeira, participando com $6 \%$ do total da produção. Constata-se o crescente destaque do setor florestal brasileiro na economia nacional, com um PIB florestal de aproximadamente US\$ 21 bilhões, com exportações de US\$ 4 bilhões, no ano de 2001 (NOCE et al., 2005). Entretanto, para atender a procura por madeira e produtos advindos da madeira nos mercados interno e externo, novas áreas devem ser estabelecidas para implantação de povoamentos florestais (ROCHADELLI et al., 2008).

A implantação de povoamentos florestais em novas áreas exige o conhecimento do meio físico dos locais onde se quer desenvolver o plantio. Essas características devem ser comparadas com as exigências adaptativas das espécies desejadas, num processo denominado zoneamento. Os zoneamentos agrícolas, agroecológicos ou agroambientais têm como objetivo principal identificar as áreas adequadas para a implantação de determinadas atividades agropecuárias e florestais, com base principalmente em estudos sobre o meio biofísico (CHAVES, 2000).

Observando os problemas dos plantios florestais do estado de Minas Gerais e fazendo um levantamento das condições bioclimáticas da região, Golfari (1975) elaborou um estudo da influência dos fatores do complexo ambiental sobre o crescimento das espécies florestais nas diferentes condições em que se encontravam. Semelhante trabalho foi feito para a região Nordeste (GOLFARI; CASER, 1977), resultando assim em um melhor direcionamento para o plantio das espécies florestais.

Golfari et al. (1978) dividiram o Brasil em vinte e seis regiões, de acordo com os caracteres altitude, tipo de vegetação, tipo de clima, temperatura média anual, presença de geadas, precipitação média anual, regime de precipitação e deficiência hídrica, na elaboração de um zoneamento ecológico para reflorestamento. Dando continuidade ao trabalho de Golfari, Carpanezzi et al. (1988), Nappo et al. (2005), Marin e Barreto Júnior (2005) e Macedo et al. (2005) realizaram zoneamentos ecológicos para diferentes regiões do país.

Para o Distrito Federal, foi encontrado na literatura apenas um zoneamento destinado à produção florestal. Ele se encontra no plano de manejo florestal em regime sustentável e de integração social da PROFLORA S/A - Florestamento e Reflorestamento -, em incorporação realizada pela cooperativa Ecooidéia (ECOOIDÉIA, 2008).

Apesar do Distrito Federal não apresentar tradição silvicultural, alguns povoamentos florestais de pinus e eucalipto já foram introduzidos. Segundo Ecooidéia (2008), a empresa responsável pelo plantio da maioria dos povoamentos do Distrito Federal (DF) foi a PROFLORA S/A. Nos anos de 1976 a 1985, ela realizou o plantio de 12.723,68 ha de eucalipto, 5.434,18 ha de pinus, 780 ha de manga e 329,56 ha de nativas. Outros povoamentos de Pinus sp. e Eucalyptus sp. puderam ser identificados no Distrito Federal nos trabalhos de Botelho et al. (2000), Melo e Resck (2002), Melo et al. (2004), Gonçalves (2007a) e Moraes Neto (2009).

A realização de um zoneamento ecológico é um procedimento fundamental para o sucesso na implantação de um empreendimento florestal. Sendo assim, o objetivo deste trabalho foi elaborar o zoneamento ecológico de pequena escala para o Distrito Federal e verificar a adaptabilidade de espécies florestais tradicionais, por meio de técnicas de geoprocessamento.

\section{MATERIAL E MÉTODOS}

\section{Caracterização da área de estudo}

O zoneamento ecológico de pequena escala para as espécies florestais tradicionais foi realizado para o Distrito Federal (Figura 1). Situado na porção central do Planalto Central Brasileiro $\left(15^{\circ} 30^{\prime}\right.$ a $16^{\circ} 03^{\prime} \mathrm{S}$ e $47^{\circ} 18^{\prime}$ a $48^{\circ} 17^{\prime} \mathrm{W} ; 750$ a $1350 \mathrm{~m}$ altitude) (EMERY et al., 2006) e coberto em sua totalidade por fisionomias do bioma Cerrado (MACHADO et al., 2004), o Distrito Federal ocupa uma área de $5.801,937 \mathrm{~km}^{2}$ (INSTITUTO BRASILEIRO DE GEOGRAFIA E ESTATÍSTICA (IBGE), 2010). 
Segundo Baptista (1998), o Distrito Federal possui clima tropical, com uma estação fria e seca (inverno) e uma estação quente e chuvosa (verão), sendo classificado, segundo Köppen, como do tipo tropical (Aw) e tropical de altitude (Cwa, Cwb). As classes de solo predominantes são Latossolo Vermelho (38,68\%), Latossolo Vermelho-Amarelo (15,84\%) e Cambissolo Distrófico $(31,02 \%)$ (EMPRESA BRASILEIRA DE PESQUISA AGROPECUÁRIA (EMBRAPA), 1978).

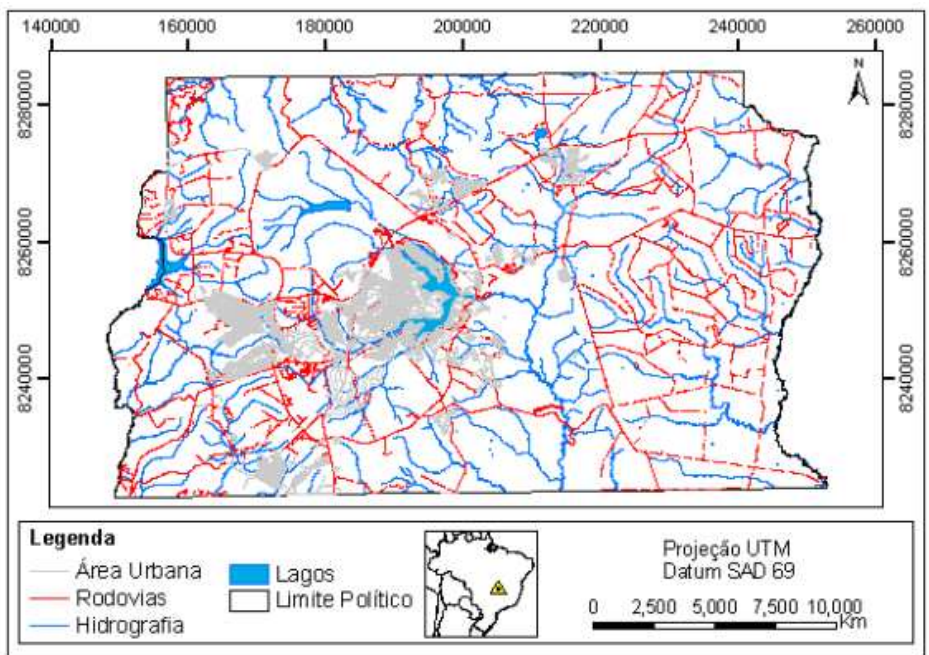

Figura 1. Mapa de localização do Distrito Federal.

Figure 1. Location map of Distrito Federal.

\section{Espécies utilizadas e aptidão edafoclimática}

Foram selecionadas 11 espécies arbóreas de interesse florestal, popularmente conhecidas como pinus, eucalipto, seringueira e teca (Tabela 1). A escolha dessas espécies foi baseada no fato de os povoamentos florestais de produção no Brasil serem compostos principalmente por espécies de pinus e eucalipto. Há também uma grande extensão de plantios constituídos de outros gêneros, como acácia (Acacia spp.), seringueira (Hevea brasiliensis), teca (Tectona grandis) e araucária (Araucaria angustifolia), entre outros (DUBOC, 2008).

Tabela 1. Lista das espécies selecionadas contendo nomes popular e científico.

Table 1. List of selected tree species including scientific and common names.

\begin{tabular}{ll}
\hline Nome popular & Nome científico \\
\hline Pínus & Pinus caribaea Morelet var. caribaea \\
Pínus & Pinus caribaea Morelet var. hondurensis (Sénécl.) W. H. G. Barrett \& Golfari \\
Pínus & Pinus caribaea Morelet var. bahamensis (Griseb.) W. H. G. Barrett \& Golfari \\
Pínus & Pinus elliottii Engelm. var. elliottii \\
Eucalipto & Eucalyptus camaldulensis Dehnh. \\
Eucalipto & Eucalyptus urophylla S. T. Blake \\
Eucalipto & Eucalyptus grandis W. Hill \\
Eucalipto & Corymbia citriodora ( Hook. ) K. D. Hill \& L. A. S. Johnson (ex Eucalyptus citriodora) \\
Eucalipto & Corymbia torelliana (F. Muell.) K. D. Hill \& L. A. S. Johnson (ex Eucalyptus torelliana) \\
Seringueira & Hevea brasiliensis (Willd. ex A. Juss.) Müll. Arg. \\
Teca & Tectona grandis L. f. \\
\hline
\end{tabular}

Cada espécie necessita de condições edafoclimáticas específicas para se desenvolver. A identificação das exigências adaptativas das espécies escolhidas foi baseada nas condições edafoclimáticas dos locais de origem das espécies e em locais onde houve sucesso na produção dos povoamentos. Os requisitos edafoclimáticos utilizados foram temperaturas mínima e máxima $\left({ }^{\circ} \mathrm{C}\right)$, precipitação média anual $(\mathrm{mm})$, déficit hídrico anual $(\mathrm{mm})$, tipo de solo e altitude $(\mathrm{m})$ (Tabela 2). 
O parâmetro adotado para solos foi que eles fossem de profundos $(>100 \mathrm{~cm} \mathrm{e} \leq 200 \mathrm{~cm})$ a muito profundos $(>200 \mathrm{~cm})$ e bem drenados, potencializando o desenvolvimento das espécies (EMBRAPA, 2006). As exigências adaptativas das três variedades de $P$. caribaea foram as mesmas, sendo analisadas em nível de espécie.

Tabela 2. Exigências ambientais estabelecidas para a implantação de povoamentos de produção para cada uma das espécies.

Table 2. Physical requirements set for the standard production development of each tree species.

\begin{tabular}{lccccc}
\hline \multirow{2}{*}{ Espécies } & \multicolumn{3}{c}{ Aspectos climáticos } & \multicolumn{2}{c}{ Aspectos edáficos } \\
\cline { 2 - 6 } & T $\left({ }^{\circ} \mathbf{C}\right)$ & PMA $(\mathbf{m m})$ & DHA $(\mathbf{m m})$ & Solos & Altitude $(\mathbf{m})$ \\
\hline Pinus caribaea & 13 a 26 & 900 a 1800 & até 300 & 100 a 1300 \\
Pinus elliottii & 18 a 41 & 1400 a 1800 & até 200 & 600 a 1800 \\
Eucalyptus camaldulensis & 11 a 35 & 700 a 1800 & até 400 & Profundos a & 100 a 1000 \\
Eucalyptus urophylla & 8 a 29 & 900 a 1800 & até 400 & muito & 200 a 1400 \\
Eucalyptus grandis & 5 a 32 & 1300 a 1800 & até 300 & profundos e & 200 a 1000 \\
Corymbia citriodora & 5 a 35 & 900 a 1800 & até 250 & bem drenados & 100 a 200 \\
Corymbia torelliana & 10 a 29 & 1200 a 1300 & até 250 & até 900 \\
Hevea brasiliensis & 11 a 29 & 1300 a 3000 & até 300 & até 1300 \\
Tectona grandis & 2 a 42 & 800 a 2500 & até 100 & &
\end{tabular}

Nota: Temperatura (T), Precipitação Média Anual (PMA) e Déficit Hídrico Anual (DHA).

Fonte: adaptado de Golfari, 1975, e Nappo et al., 2005.

\section{Construção e processamento do banco de dados}

Os dados do Distrito Federal de clima, hidrografia, classes de solo e limites políticos foram disponibilizados pela Agência de Desenvolvimento do Distrito Federal (Terracap), estando no formato vetorial (shapefile). Os dados de precipitação e uso do solo, no formato matricial, foram extraídos da base de dados de Gonçalves (2007b). Os dados sobre unidades de conservação, também no formato vetorial, foram disponibilizados pelo Instituto Brasileiro do Meio Ambiente e dos Recursos Naturais Renováveis (IBAMA).

Os dados de altitude foram extraídos de imagens no formato matricial do satélite ASTER Global Digital Elevation Model (GDEM), produzido pela Japan's Ministry of Economy, Trade and Industry (METI) e pela National Aeronautics and Space Administration (NASA). Esses dados altimétricos apresentam resolução espacial de 30 m e datum WGS-84 (METI; NASA, 2009). Os valores de déficit hídrico foram obtidos a partir do trabalho de Silva et al. (2003), que apresenta um mapa da deficiência hídrica anual para o estado de Goiás.

Depois de obtidos os dados, eles foram processados para adequação ao processo de zoneamento. O software utilizado foi o ArcGIS® versão 9.3, desenvolvido pelo Environmental Systems Research Institute (ESRI, 2008). Os dados processados tiveram resolução espacial de trinta metros e escala 1:400.000. Eles foram projetados para o sistema de projeção UTM, zona 23 e datum SAD 69.

O território do Distrito Federal foi dividido em regiões que se diferenciam, entre si, pelas variadas condições de precipitação, clima, déficit hídrico, altitude e classes de solo (Figura 2). Essas informações definiram as condições em que as espécies selecionadas podem apresentar um bom desenvolvimento e especificaram as localidades em que podem ser introduzidos os povoamentos florestais.

Os dados de declividade, classes de solo, uso do solo, hidrografia e unidades de conservação definiram as localidades não passíveis de implantação dos povoamentos (Figura 3). A partir da declividade, hidrografia (lagos) e classes de solo (solo hidromórfico), foram calculadas as Áreas de Preservação Permanente (APPs), que, de acordo com a legislação vigente, não podem se usadas para plantio. O uso do solo e as unidades de conservação definiram áreas que estavam em uso para outras finalidades (uso urbano e Unidades de Proteção Integral), excluindo-se também a possibilidade de plantio nesses locais.

As características físicas do território do Distrito Federal e as exigências ambientais das espécies indicadas foram relacionadas, sobrepondo-se todas as matrizes temáticas. Mapas das áreas de aptidão potencial foram gerados para a implantação de povoamentos de produção para as espécies selecionadas. 
A resolução espacial dos mapas gerados foi de trinta metros. Os valores das áreas de aptidão potencial foram calculados multiplicando-se a área de cada célula $\left(900 \mathrm{~m}^{2}\right)$ pelo número de células da área, tendo em vista que os mapas matriciais foram gerados em resolução espacial 30 × $30 \mathrm{~m}$.
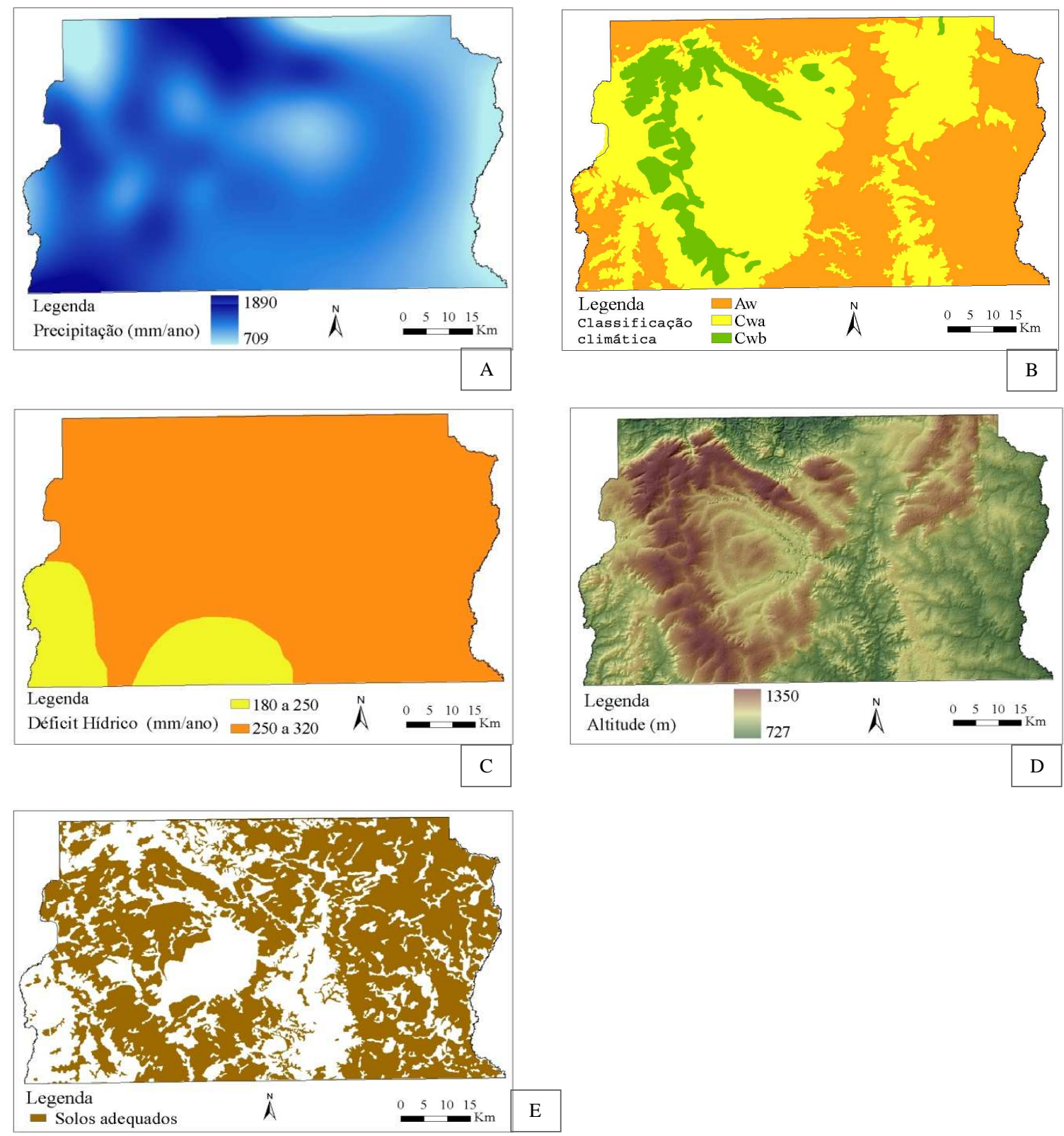

Figura 2. Espacialização das variáveis utilizadas no zoneamento agroecológico das espécies florestais no Distrito Federal: (A) precipitação média; (B) classificação climática de Köppen; (C) déficit hídrico; (D) Modelo de Elevação Digital; (E) classes de solo adequadas ao plantio florestal.

Figure 2. Geographical distribution of variables used in agro-ecological zoning of forest species in the Distrito Federal: (A) mean precipitation; (B) climatic classification of Köppen; (C) water deficit; (D) Digital Elevation Model; (E) suitable classes of soil for forestation. 

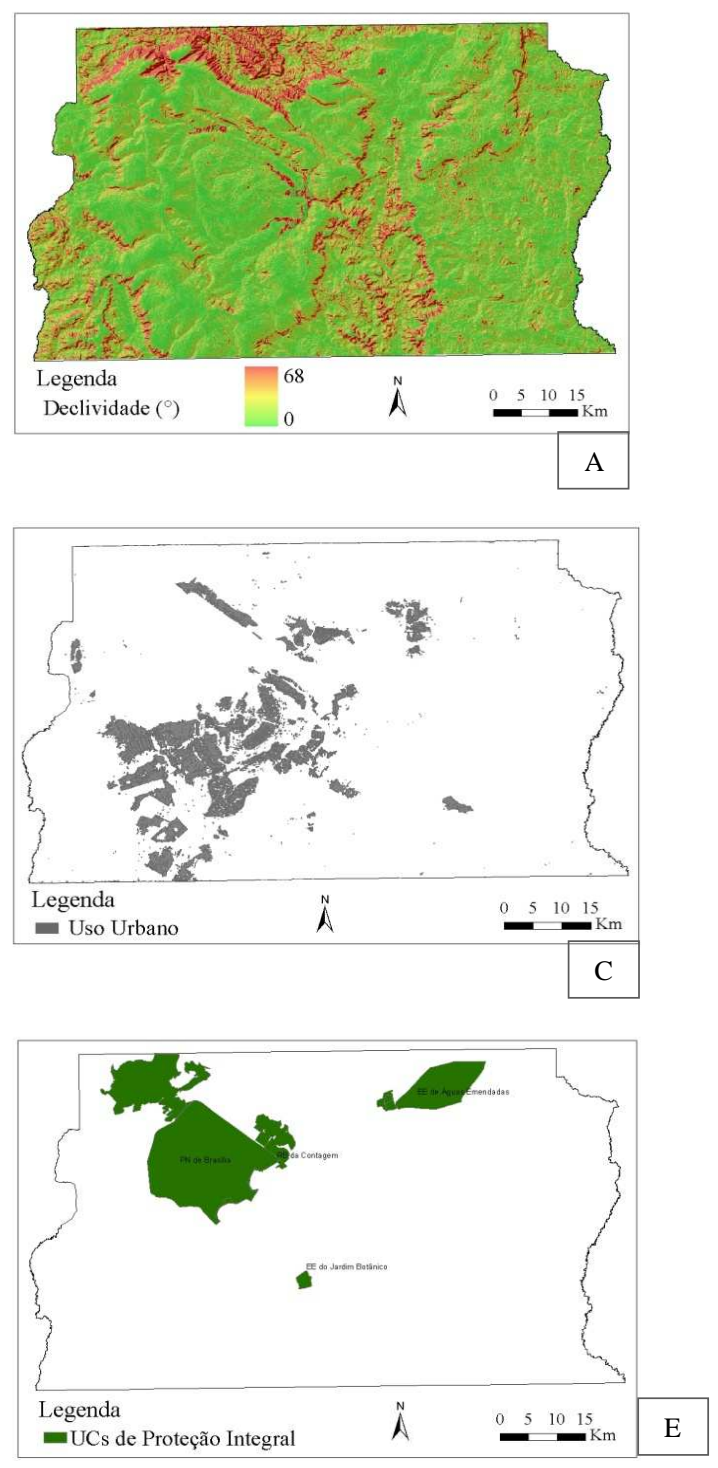
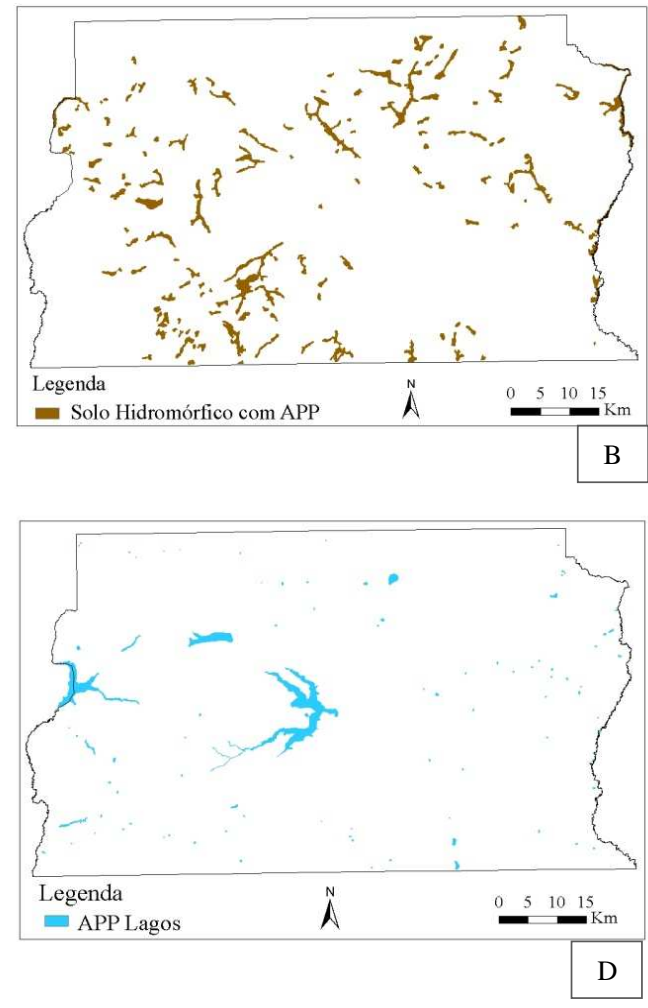

Figura 3. Espacialização de características que definiram as localidades não passíveis de implantação dos povoamentos no Distrito Federal: (A) declividade; (B) solos hidromórficos com APPs; (C) uso urbano; (D) lagos com APPs; (E) Unidades de Proteção Integral.

Figure 3. Geographical distribution of features that define the regions not subject to forestation in the Distrito Federal: (A) slope; (B) hydromorfic soils and buffer protection zones; (C) urban use; (D) water bodies and buffer protection zones; (E) Protected Areas.

\section{RESULTADOS E DISCUSSÃO}

O local de estudo apresentou áreas de aptidão florestal para o plantio de oito das onze espécies selecionadas (Tabela 3). A potencialidade de cultivo das espécies no território foi definida pelo atendimento das exigências climáticas das mesmas durante a sobreposição dos dados do meio físico do Distrito Federal. Os mapas de área potencial gerados estão na escala 1:400.000 (Figura 4).

A espécie Pinus caribaea não apresentou restrição aos parâmetros altitude, precipitação e déficit hídrico. A característica que mais influenciou na distribuição das áreas potenciais foi o clima (Cwa temperatura média do mês mais frio menor que $18{ }^{\circ} \mathrm{C}$ e do mês mais quente maior ou igual a $22{ }^{\circ} \mathrm{C}$ ). A área potencial para o cultivo de $P$. elliottii foi restringida pela combinação dos valores de déficit hídrico (até $200 \mathrm{~mm} / \mathrm{ano}$ ), pela precipitação (1400 a $1800 \mathrm{~mm} / \mathrm{ano})$ e pelo clima (Aw - temperatura média do mês mais frio maior ou igual a $18{ }^{\circ} \mathrm{C}$ e do mês mais quente maior ou igual a $22{ }^{\circ} \mathrm{C}$ ). 
Tabela 3. Área potencial para o cultivo das espécies no DF, Brasil.

Table 3. Suitable areas for tree species cultivation in the DF, Brazil.

\begin{tabular}{lcc}
\hline Espécies & Área potencial (ha) & Porcentagem do DF $\mathbf{( \% )}$ \\
\hline Pinus caribaea & $126.269,55$ & 21,76 \\
Pinus elliottii & $2.074,14$ & 0,35 \\
Eucalyptus camaldulensis & $127.920,24$ & 22,04 \\
Eucalyptus urophylla & $2.300,49$ & 0,39 \\
Eucalyptus grandis & $87.691,77$ & 15,11 \\
Corymbia citriodora & 86,94 & 0,014 \\
\hline
\end{tabular}

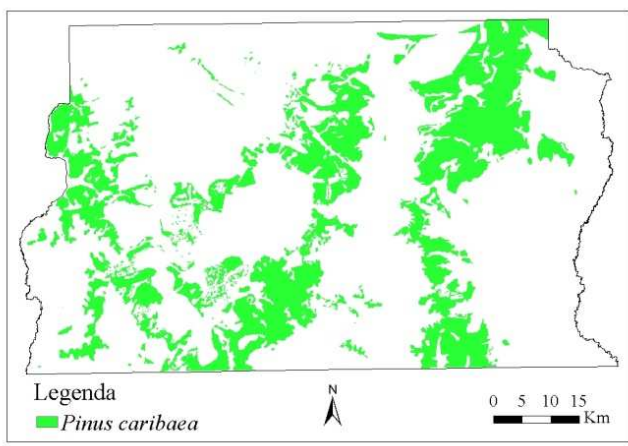

A

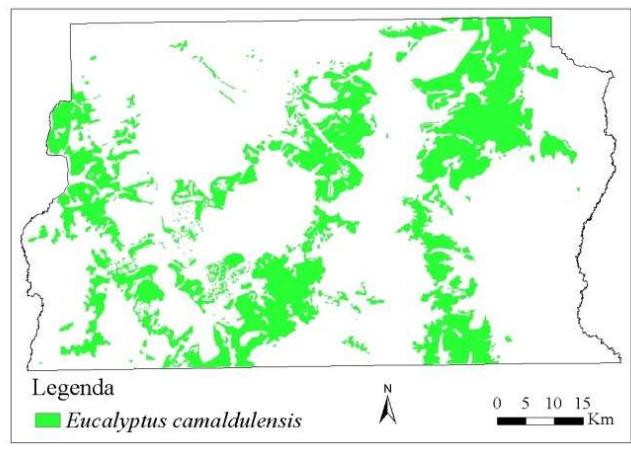

$\mathrm{C}$

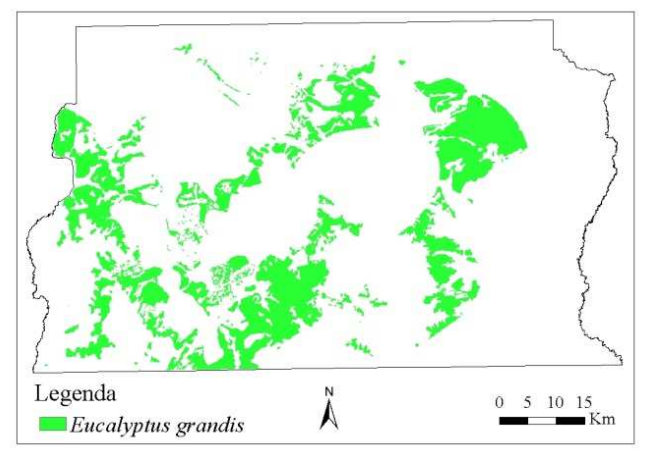

$\mathrm{E}$
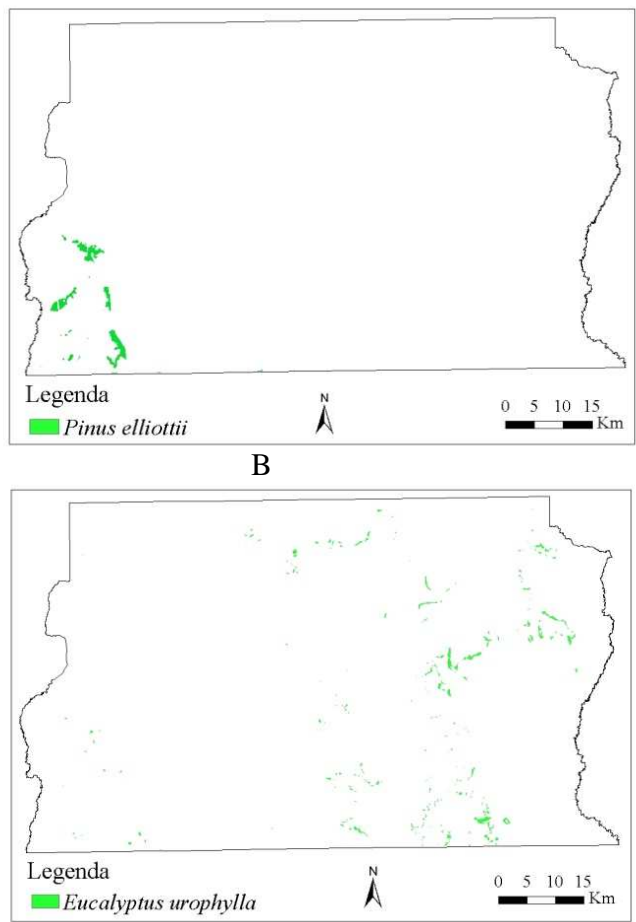

$\mathrm{D}$

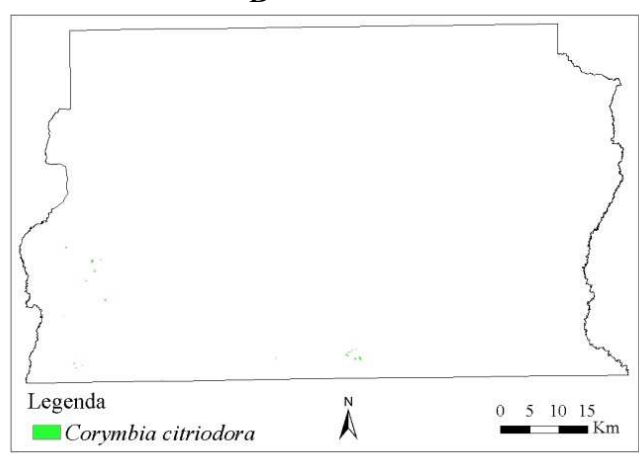

$\mathrm{F}$

Figura 4. Mapa da distribuição espacial de áreas aptas ao plantio de espécies no Distrito Federal: (A) Pinus caribaea; (B) Pinus elliotti; (C) Eucalyptus camaldulensis; (D) Eucalyptus urophylla; (E) Eucalyptus grandis; (F) Corymbia citriodora.

Figure 4. Map of suitable areas for cultivation of species in the Distrito Federal: (A) Pinus caribaea; (B) Pinus elliotti; (C) Eucalyptus camaldulensis; (D) Eucalyptus urophylla; (E) Eucalyptus grandis; (F) Corymbia citriodora. 
E. camaldulensis apresentou distribuição muito semelhante à $P$. caribaea, tendo como principal influência o clima (Cwa). A espécie E. urophylla foi influenciada pelo clima (Cwa). As áreas de $E$. grandis foram restringidas pelo clima Cwa e pela precipitação (1300 a $1800 \mathrm{~mm} / \mathrm{ano})$. A espécie $C$. citriodora foi influenciada pelo clima Cwa, mas principalmente pelo déficit hídrico (180 a $250 \mathrm{~mm} / \mathrm{ano}$ ).

As espécies C. torelliana, Hevea brasiliensis e Tectona grandis não apresentaram áreas de aptidão potencial no Distrito Federal. A primeira não se adequou ao território, pois sua exigência de altitude é de 100 a 200 m, enquanto a altitude mínima do Distrito Federal é de 727 m. Para Hevea brasiliensis não houve uma área em comum no cruzamento dos dados que atendesse as exigências da espécie. Tectona grandis tolera um déficit hídrico de até $100 \mathrm{~mm} / \mathrm{ano}$, sendo que o mínimo do DF é de $180 \mathrm{~mm} / \mathrm{ano}$.

\section{CONCLUSÕES}

- O território do Distrito Federal apresentou aptidão florestal para espécies de relevante interesse comercial e foi possível determinar as áreas potenciais de implantação dos cultivos florestais de produção. O uso da ferramenta do Sistema de Informação Geográfica (SIG) possibilitou modelar e determinar com precisão as áreas potenciais para implantação dos cultivos florestais de cada espécie estudada, a partir do cruzamento dos dados temáticos utilizados neste estudo.

- Entre as espécies estudadas, Pinus caribaea var. caribaea, P. caribaea var. hondurensis, P. caribaea var. bahamensis, Eucalyptus camaldulensis e E. grandis apresentaram maior potencial de cultivo no Distrito Federal. As espécies P. elliottii var. elliottii, E. urophylla e Corymbia citriodora apresentaram potencial de cultivo restrito a pequenas áreas. Corymbia torelliana, Hevea brasiliensis e Tectona grandis não apresentaram potencial de cultivo no DF.

\section{REFERÊNCIAS}

BAPTISTA, G. M. M. Caracterização climatológica do Distrito Federal. In: IEMA/SEMATEC/UnB, Inventário Hidrogeológico e dos Recursos Hídricos Superficiais do Distrito Federal. Brasília. v. 1, p. 187 - 208, 1998.

BOTELHO, G. M. L.; SANTANA, M. A. E.; ALVES, M. V. S. Caracterização química, durabilidade natural e tratabilidade da madeira de seis espécies de eucaliptos plantadas no Distrito Federal. Revista Árvore, Viçosa-MG, v. 24, n. 1, p. 115 - 121, 2000.

CARPANEZZI, A. A.; PEREIRA, J. C. D.; CARVALHO, P. E. R.; REIS, A.; VIEIRA, A. R. R.; ROTTA, E.; STURION, J. A.; RAUEN, M. J.; SILVEIRA, R. A. Zoneamento ecológico para plantios florestais no estado de Santa Catarina. Curitiba: EMBRAPA-CNPF, 1988. 113 p. (EMBRAPA-CNPF. Documentos, 21).

CARVALHO, R. M. M. A.; SOARES, T. S.; VALVERDE, S. R. Caracterização do setor florestal: uma abordagem comparativa com outros setores da economia. Ciência Florestal, Santa Maria, v. 15, n. 1, p. $105-118,2005$.

CHAVES, F. T. Planejamento virtual: o zoneamento ecológico-econômico (ZEE) na Amazônia enquanto instrumento de política ambiental e territorial. 2000. 109 f. Dissertação (Mestrado em Gestão Econômica do Meio Ambiente) - Instituto de Ciências Humanas, Universidade de Brasília, Brasília, 2000.

DUBOC, E. Oportunidades do setor florestal brasileiro. Planaltina: Embrapa Cerrados, 2008. 42 p. (Embrapa Cerrados. Documentos, 218).

ECOOIDÉIA. Plano de Manejo Florestal em Regime Sustentável e de Integração Social da PROFLORA S/A - Florestamento e Reflorestamento - Em incorporação. Terracap, Brasília, 2008.

EMERY, E. O.; BROWN JR., K. S.; PINHEIRO, C. E. G. As borboletas (Lepidoptera, Papilionoidea) do Distrito Federal, Brasil. Revista Brasileira de Entomologia, São Paulo, v. 50, n. 1, 2006. 
EMPRESA BRASILEIRA DE PESQUISA AGROPECUÁRIA (EMBRAPA). Serviço Nacional de Levantamento e Conservação dos Solos. Levantamento de Reconhecimento dos Solos do Distrito Federal. Escala 1:100.000. Rio de Janeiro. EMBRAPA. SNLCS. Boletim Técnico. 1978. 455 p.

Centro Nacional e Pesquisa em Solos. Sistema Brasileiro de Classificação de Solos. Brasília:Embrapa-SPI; Rio de Janeiro: Embrapa-Solos, 2006. 306 p.

ENVIRONMENTAL SYSTEMS RESEARCH INSTITUTE (ESRI). ArcGIS. Professional GIS for the desktop, versão 9.3, 2008.

GOLFARI, L. Zoneamento ecológico do estado de Minas Gerais para reflorestamento. Belo Horizonte: Centro de Pesquisa Florestal da Região do Cerrado, 1975. 65 p. (PRODEPEF. Série Técnica, 3).

GOLFARI, L.; CASER, R. L. Zoneamento ecológico da região Nordeste para experimentação florestal. Belo Horizonte: Centro de Pesquisa Florestal da Região do Cerrado, 1977. 116 p. (PRODEPEF. Série Técnica, 10).

GOLFARI, L.; CASER, R. L.; MOURA, V. P. G. Zoneamento ecológico esquemático para reflorestamento no Brasil ( $2^{\mathbf{a}}$ aproximação). Belo Horizonte: Centro de Pesquisa Florestal da Região do Cerrado, 1978. 66 p. (PRODEPEF. Série Técnica, 11).

GONÇAlveS, A. R. Banco de sementes do solo de sub-bosque de Pinus sp. e Eucalyptus sp. abandonado na Florestal Nacional de Brasília. 2007. 93 f. Dissertação (Mestrado em Ciências Florestais) - Departamento de Engenharia Florestal, Universidade de Brasília, Brasília, 2007a.

GONÇALVES, T. D. Geoprocessamento como ferramenta de apoio à gestão dos recursos hídricos subterrâneos do Distrito Federal. 2007. 88 f. Dissertação (Mestrado em Geologia) - Instituto de Geociências, Universidade de Brasília, Brasília, 2007b.

INSTITUTO BRASILEIRO DE GEOGRAFIA E ESTATÍSTICA (IBGE). Distrito Federal. Disponível em: 〈http://www.ibge.gov.br/estadosat/perfil.php?sigla=df >. Acesso em: 18/01/2010.

JAPAN'S MINISTRY OF ECONOMY, TRADE AND INDUSTRY, NASA - NATIONAL AERONAUTICS AND SPACE ADMINISTRATION (METI). ASTER Global Digital Elevation Model (GDEM). 2009. Disponível em: <http://free-gis-data.blogspot.com/2009/04/aster-global-digitalelevation-model.html>. Acesso em: 01/02/2010.

MACEDO, R. L. G.; GOMES, J. E.; VENTURIN, N.; SALGADO, B. G. Desenvolvimento inicial de Tectona grandis L.f. (Teca) em diferentes espaçamentos no município de Paracatu, MG. Cerne, Lavras, v. 11, n. 1, p. 61 - 69, 2005.

MACHADO, R. B.; RAMOS NETO, M. B.; PEREIRA, P. G. P.; CALDAS, E.; GONÇALVES, D. A.; SANTOS, N. S.; TABOR, K.; STEININGER, M. Estimativas de perda da área do Cerrado brasileiro. 2004. Relatório técnico não publicado. Conservação Internacional, Brasília, DF.

MARIN, F. R.; BARRETO JÚNIOR, C. E. F. Zoneamento agroclimático da heveicultura no estado de São Paulo. In: CONGRESSO BRASILEIRO DE AGROMETEOROLOGIA, 14., 2005, Campinas. Anais... Campinas: UNICAMP, 2005. 2 p.

MELO, J. T.; RESCK, D. V. S. Retorno, ao solo, de nutrientes de serapilheira de pinus no cerrado do Distrito Federal. Planaltina, DF. Embrapa Cerrados, 2002. Boletim de Pesquisa e Desenvolvimento, n. $75,18 \mathrm{p}$.

MELO, J. T.; RESCK, D. V. S.; GOMES, A. C. Efeito de procedências de Eucalyptus camaldulensis sobre os teores de nutrientes e de carbono orgânico do solo no cerrado. Planaltina, DF. Embrapa Cerrados, 2004. Boletim de Pesquisa e Desenvolvimento, n. 142, 17 p.

MORAES NETO, S. P. de. Estimativa de volume de Pinus caribaea var. hondurensis no cerrado do Distrito Federal, DF. Planaltina, DF. Embrapa Cerrados, 2009. Boletim de Pesquisa e Desenvolvimento, n. 231,16 p. 
NAPPO, M. E.; NAPPO, A. E.; PAIVA, H. N. Zoneamento ecológico de pequena escala para nove espécies arbóreas de interesse florestal no estado de Minas Gerais. Revista Científica Eletrônica de Engenharia Florestal, 5. ed., 2005.

NOCE, R., Silva, M. L., SOARES, T. S., CARVAlHO, R. M. M. A. Análise de risco e retorno do setor florestal: produtos de madeira. Revista Árvore, Viçosa, v. 29, n. 1, 2005.

ROCHADELLI, R.; SILVA, J. C. G. L.; RODRIGUES, F.; SCHNEIDER, A. V.; PETLA, D. Expansão florestal via fomento no Segundo Planalto Paranaense: uma abordagem a partir da estrutura fundiária das propriedades rurais da região. Revista Cerne, Lavras, v. 14, n. 2, p. 163 - 169, 2008.

SILVA, F. A. M.; FEITOZA, L.; EVANGELISTA, B. A.; ASSAD, E. D. Áreas aptas e necessidade de irrigação para a cultura do café (Coffea arabica L.) no estado de Goiás. In: CONGRESSO BRASILEIRO DE AGROMETEOROLOGIA, 13., 2003, Santa Maria. Anais... Santa Maria, 2003, p. 261 - 262.

SILVA, K. R.; MINETTI, L. J.; FIEDLER, N. C.; VENTUROLI, F.; MACHADO, E. G. B.; SOUZA, A. P. Custos e rendimentos operacionais de um plantio de eucalipto em região de cerrado. Revista Árvore, Viçosa, MG, v. 28, n. 3, p. 361 - 366, 2004. 